\title{
Mecanismos associados à tolerância ao alumínio em plantas
}

\section{Associated mechanisms of aluminum tolerance in plants}

\author{
Irineu Hartwig ${ }^{1 *}$; Antônio Costa de Oliveira²; Fernando Irajá Félix de Carvalho ${ }^{2}$; \\ Ivandro Bertan ${ }^{1}$; José Antônio Gonzalez da Silva ${ }^{3}$; \\ Douglas André Mallmann Schmidt"; Igor Pires Valério4; Luciano Carlos Maia \\ Daniel Andrei Robe Fonseca ${ }^{6}$; Cecília Estima Sacramento dos Reis ${ }^{7}$
}

\section{Resumo}

\begin{abstract}
A toxicidade do alumínio é um dos principais fatores limitantes do desenvolvimento das plantas em solos ácidos. Pelo fato da utilização de corretivos da acidez do solo não ser a estratégia mais viável em muitas situações com solos ácidos (por razões técnicas e econômicas), o desenvolvimento de genótipos tolerantes ao $\mathrm{Al}$ tem sido o caminho mais focado, assim a investigação dos mecanismos de tolerância bem como as bases genéticas da tolerância ao $\mathrm{Al}$ têm merecido atenção especial pela pesquisa científica. Nos últimos anos, foi gerado um significativo progresso no entendimento das bases dos mecanismos de tolerância ao Al, assim como no desenvolvimento de cultivares mais adaptados as condições de solos ácidos. Os mecanismos de tolerância ao $\mathrm{Al}$ conhecidos se resumem basicamente em duas classes: os que agem no sentido de expulsar o $\mathrm{Al}$ depois de absorvido ou de impedir sua entrada pela raiz e os mecanismos de desintoxicação, complexando o $\mathrm{Al}$ em organelas específicas da planta, principalmente nos vacúolos. Em inúmeras espécies, mecanismos fisiológicos tem sido reportados como responsáveis pela ativação de ácidos orgânicos (principalmente citrato e malato) que atuam como agentes quelantes do Al, porém muitos processos ainda não são bem entendidos e esclarecidos. Atualmente, se começa a entender melhor um segundo mecanismo de tolerância ao $\mathrm{Al}$ que envolve a desintoxicação interna do $\mathrm{Al}$ através da complexação por ácidos orgânicos e o seqüestro destes complexos pelos vacúolos. Outros mecanismos potenciais são alvo de especulações e discussões.
\end{abstract}

Palavras-chave: Al, solos ácidos, ácidos orgânicos, exsudatos

\begin{abstract}
Aluminum toxicity is one of the major limiting factor regarding plant development in acid soils. The use of liming for correcting soil $\mathrm{pH}$ is not viable for some of acid soil areas (technique or economic reasons), making the development of $\mathrm{Al}$ tolerant genotypes the best alternative. Thus, the tolerance mechanisms as well as the genetic basis of $\mathrm{Al}$ tolerance has deserved special attention in the scientific community. In
\end{abstract}

\footnotetext{
1 Eng. Agr., M.Sc., D.Sc. em Agronomia, Pós-Doutorando Júnior (CNPq). Centro de Genômica e Fitomelhoramento (CGF) Faculdade de Agronomia “Eliseu Maciel” (FAEM)/Universidade Federal de Pelotas (UFPel). Pelotas, RS. E-mail: iriwig@gmail.com

2 Eng. Agr., M.Sc., PhD. em Genética e Melhoramento de Plantas - Docente no CGF/FAEM/UFPel. Pelotas, RS.

3 Eng. Agr., M.Sc., D.Sc em Agronomia - Docente do Departamento de Estudos Agrários da Universidade Regional do Noroeste do Estado do Rio Grande do Sul (UNIJUÍ). Ijuí, RS.

4 Eng. Agr., M.Sc., Doutorando em Agronomia (CAPES). CGF/FAEM/UFPel. Pelotas, RS.

5 Eng. Agr., M.Sc., Doutorando em Agronomia (CNPq). CGF/FAEM/UFPel. Pelotas, RS.

6 Graduando em Agronomia, Bolsista de Apoio Técnico (CNPq). CGF/FAEM/UFPel. Pelotas, RS.

7 Bacharel e Licenciada em Química, Mestranda em Agronomia (CAPES). Departamento de Solos - FAEM/UFPel. Pelotas, RS.

* Autor para correspondência
} 
the last years, a significant progress has been achieved towards these goals, as well as in developing cultivars adapted to acid soils. The Al tolerance mechanisms are divided basically in two classes: the exclusion mechanisms that act after absorption or blocking its entry in the root system and those involved in detoxification, complexing the $\mathrm{Al}$ in specific organelles, mainly in the vacuoles. In many species, physiological mechanisms have been reported as responsible for the activation of organic acids (mainly citrate and malate) that act as Al quelating agents, however many process are not yet understood and cleared. Currently, the basis for the internal detoxification is becoming clear through organic acid complexes and there sequestering by the vacuoles. Other potential mechanisms are the target for discussions.

Key words: Al, acid soils, organic acids, exudates

\section{Introdução}

Uma das principais limitações dos cultivos agrícolas nos trópicos e por conseqüência do incremento da produção de alimentos está relacionada a ocorrência de solos ácidos. Em torno de $30 \%$ da área da crosta terrestre é composta de solos ácidos ( $\mathrm{pH} \leq 5,5)$, o que corresponde a mais de $50 \%$ dos solos potencialmente agricultáveis no mundo, sendo que as regiões tropicais e subtropicais contam com a maior porção (60\%) (VON UEXKÜLL; MUTERT, 1995).

O efeito da acidez do solo sobre as plantas provém principalmente pelas alterações químicas, entre elas: solubilização na solução do solo do alumínio (Al), manganês $(\mathrm{Mn})$ e ferro $(\mathrm{Fe})$ atingindo níveis tóxicos, assim como a complexação de alguns elementos essenciais, sendo o fósforo (P) o mais limitado (KOCHIAN, 1995).

O Al em níveis tóxicos na solução do solo, interfere na movimentação do fósforo, cálcio, magnésio e molibidênio (OLMOS; CAMARGO, 1976). Em cultivo hidropônico com tratamentos com Al, Freitas et al. (2006) observaram significativa redução da absorção dos macronutrientes $\mathrm{P}, \mathrm{Mg}, \mathrm{Ca}$ e $\mathrm{K}$ em genótipos de arroz. O impacto negativo destes solos sobre as principais culturas, e em especial sobre as que produzem grãos é evidente e amplamente discutida na literatura científica. O Al tóxico na solução do solo inibe o crescimento e o desenvolvimento das raízes, alterando a absorção de água e nutrientes, e por conseqüência o desenvolvimento das plantas é reduzido.
Uma forma de corrigir a acidez do solo é através da aplicação de calcário agrícola $\left(\mathrm{CaCO}_{3}+\mathrm{MgCO}_{3}\right)$, porém muitas vezes não é uma opção economicamente viável para os produtores menos capitalizados, além de corrigir apenas camadas superficiais, não sendo efetivo na correção da acidez do subsolo, devido à baixa mobilidade dos componentes solúveis do calcário aplicado na superfície do solo. Cassiolato et al. (2000) mostraram que o efeito da calagem sem resíduos vegetais foi efetiva apenas nos $10 \mathrm{~cm}$ superficiais do solo, enquanto que a calagem na presença de extratos de aveia aumentou o $\mathrm{pH}$ e Ca-trocável e diminuiu o Altrocável até $20 \mathrm{~cm}$ de profundidade. Isto prova que os compostos solúveis contidos na aveia melhoram o transporte de Ca no perfil do solo, melhorando a eficiência do calcário aplicado na superfície do solo.

Neste sentido, a estratégia do melhoramento de plantas em desenvolver genótipos que tolerem a presença do Al no solo vem tendo elevada importância. Desta forma, um melhor entendimento dos mecanismos de tolerância ao Al tóxico vem sendo enfatizado pelos pesquisadores nos últimos anos, a fim de melhor compreender estes mecanismos e poder utilizar estas informações no desenvolvimento de genótipos tolerantes ao Al.

Entre os mecanismos focados pela pesquisa, os fisiológicos e bioquímicos são os mais entendidos, além da biologia molecular da tolerância ao Al, com intuito de identificar genes que possam vir a ser utilizados via biotecnologia no incremento a tolerância ao Al, principalmente em espécies onde a variabilidade natural para o caráter é baixa. 


\section{Toxicidade do Al}

É importante compreender como se manifesta a toxicidade do Al nas plantas, para melhor compreensão dos mecanismos de tolerância a este elemento. Neste caso, vários efeitos são descritos na literatura como sendo os principais envolvidos com a toxicidade do Al. Quando o $\mathrm{pH}$ do solo é $\leq 5,5$, e na presença do $\mathrm{Al}^{3+}$, o mesmo solubiliza-se na solução do solo, tornando-se potencialmente tóxico para as plantas (KOCHIAN, 1995).

Beckmann (1954) observou pela primeira vez em trigo e outros cereais, sintomas de amarelecimento e de redução de crescimento de planta, sintoma que denominou de "crestamento". O primeiro sintoma da toxicidade do $\mathrm{Al}$ detectável é extremamente rápido, em questão de minutos inibe o crescimento da raiz, resultando em redução e danos no sistema radicular (SILVA; NOVAIS; SEDIYAMA, 1984; JONES; KOCHIAN, 1995; BARCELÓ; POSCHENRIEDER, 2002).

A rápida resposta da raiz indica que num primeiro momento o $\mathrm{Al}$ inibe a expansão e elongação das células das raízes, e depois a divisão celular também passa a ser inibida (KOCHIAN, 1995; MATSUMOTO, 2000). O sítio da toxicidade do Al está localizado no ápice da raiz. Desta forma, as pesquisas de tolerância ao $\mathrm{Al}$ são focadas nestas regiões (RYAN; DITOMASO; KOCHIAN, 1993; SIVAGURU et al., 1999).

Em função da rápida reatividade do $\mathrm{Al}$, as injúrias podem ocorrer na parede celular, na membrana plasmática, no citoesqueleto e até no núcleo celular. Entretanto, a maior associação do $\mathrm{Al}$ com a raiz ocorre no apoplasto, uma pequena fração do Al rapidamente entra e interage no simplasto (SILVA et al., 2000; TAYLOR et al., 2000). O Al interage com as vias de transdução de sinais, em especial os relacionados com a homeostase e transporte do cálcio $\left(\mathrm{Ca}^{2+}\right)$, podendo alterar os níveis de $\mathrm{Ca}^{2+}$ (ZHANG; RENGEL, 1999), e pode interagir e inibir a enzima fosfolipase $\mathrm{C}$ associada às vias de transporte do $\mathrm{Ca}$ (JONES; KOCHIAN, 1995).
Embora, vários trabalhos mostrarem os efeitos negativos do Al, existem trabalhos que mostram efeitos benéficos em algumas espécies. Em arroz, Fageria e Zimmermann (1979) e Fageria, Baligar e Wright (1989) mostraram que algumas cultivares produziram maior quantidade de matéria seca sob $10 \mathrm{mg} . \mathrm{L}^{-1}$ de Al. De acordo com estes autores, uma possível explicação é o aumento da disponibilidade de Fe no meio de crescimento, resultando na hidrólise de Al e pH mais baixo. Fageria (1982) mostrou em três cultivares de arroz a maior produção de peso seco com $10 \mathrm{mg} . \mathrm{L}^{-1}$ de $\mathrm{Al}$ quando comparado com a dose zero de $\mathrm{Al}$, em qualquer dos estádios de desenvolvimento até os 80 dias avaliados no trabalho. Howeler e Cadavid (1976), Thawornwong e Diest (1974) também mostraram que o desenvolvimento do arroz foi estimulado na presença de baixas concentrações de $\mathrm{Al}$ em solução nutritiva. Isto sugere que em arroz, uma pequena quantidade de Al seja necessária para o desenvolvimento normal da planta. Grime e Hodgson (1969) apresentaram a evidência de que a resposta positiva da presença do Al a Scabiosa columbaria é devido ao deslocamento de $\mathrm{Fe}$ (pelo Al) de certos locais da planta, e com isso aprimorando a distribuição e utilização do Fe pela planta. Em espécies perenes, Salvador et al. (2000), em mudas de goiabeira (Psidium guajava L.), observaram que concentrações de $\mathrm{Al}$ abaixo de 10,0 mg. $L^{-1}$ aumentaram a altura da planta e a área foliar, respectivamente, aos 30 e 90 dias de cultivo em solução nutritiva. Para as espécies florestais do hemisfério norte, também tem sido verificado que os sintomas de toxidez somente ocorrem em concentrações acima 10,0 mg. $\mathrm{L}^{-1}$ de Al. Keltjens e Van Loenen (1989) verificaram que na presença de 30,0 mg.L. $L^{-1}$ de Al não houve redução de crescimento e de produção de massa seca em Betula pendula e Pinus silvestris, e nas espécies Larix decidua e Quercus robur houve até um estímulo na produção de massa seca na presença de Al em solução nutritiva. Também, Shier (1985) observou efeitos negativos no crescimento de Picea rubens e Abies balsamae, somente em concentrações de Al superiores a $50,0 \mathrm{mg} \cdot \mathrm{L}^{-1}$. 


\section{Mecanismos de tolerância ao Al}

A pesquisa tem distinguido os mecanismos de tolerância ao $\mathrm{Al}$ em duas classes principais: aqueles que atuam no sentido de impedir a entrada do Al pela raiz e aqueles que permitem a planta acumular o Al em locais específicos na planta. Estes processos têm sido alvo de inúmeros trabalhos científicos (KOCHIAN, 1995; KOCHIAN; JONES, 1997; MATSUMOTO, 2000; MA; RYAN; DELHAIZE, 2001; BARCELÓ; POSCHENRIEDER, 2002; MA; FURUKAWA, 2003). A maior parte das pesquisas está focada na exclusão do Al pela exsudação de ácidos orgânicos ativados pela presença do $\mathrm{Al}$ no ápice da raiz. Porém, evidências vêm sendo acumuladas num mecanismo de tolerância baseado na desintoxicação interna, onde o Al seria complexado pelos ácidos orgânicos na vias simplasta do Al. As especulações também se estendem a um maior número de mecanismos de tolerância ao $\mathrm{Al}$ e as diferenças entre espécies vegetais quanto a estes mecanismos.

\section{Exsudação de ácidos orgânicos da raiz ativados pelo Al}

Este mecanismo foi detectado primeiramente em trigo, onde genótipos tolerantes acumularam de três a oito vezes menos $\mathrm{Al}$ no ápice da raiz (sítio crítico da toxidez do $\mathrm{Al}$ ) em relação a genótipos sensíveis (RINCÓN; GONZALES, 1992; DELHAIZE; RYAN; RANDALL, 1993). Estes autores relatam também que em tecidos mais maduros das raízes a exsudação de malato não ocorreu de forma significativa, e uma forte evidência de que o Al foi excluído tanto pelas paredes celulares quanto pelas vias do simplasto, o que é consistente com a formação de ligantes orgânicos que complexam o Al na rizosfera impedindo sua entrada na raiz em genótipos considerados tolerantes.

A melhor caracterização deste processo é relatado por (DELHAIZE et al., 1993; DELHAIZE; RYAN; RANDALL, 1993; RYAN; DELHAIZE; RANDALL, 1995a; RYAN; DELHAIZE;
RANDALL, 1995b). Esses autores mostraram que a ativação do malato pelo $\mathrm{Al}$ ocorre numa região muito específica, a poucos milímetros do ápice da raiz. Também, constataram que este processo ocorre de forma muito rápida, questão de minutos, corroborando então que toda maquinaria da ativação do malato ocorre a nível celular do ápice das raízes primeiramente expostas ao Al. O contínuo processo de exsudação do malato promove a elevação de sua concentração na camada superficial do ápice radicular a níveis que quelatizam e desintoxicando uma fração significativa de $\mathrm{Al}$ na rizosfera em contato com o ápice radicular, prevenindo sua entrada na raiz. A exsudação do ácido contínua, juntamente com o crescimento das raízes no solo, mantém a quelatização como barreira sempre que novas regiões ácidas no solo são encontradas.

Posteriormente, vários trabalhos foram desenvolvidos em outras espécies, e atualmente é considerado um dos principais mecanismos relacionados à tolerância ao $\mathrm{Al}$, de acordo com a vasta literatura existente sobre a atuação de ácidos orgânicos (malato, citrato e oxalato) sobre o Al. Em geral, existem genótipos tolerantes ao $\mathrm{Al}$ em várias espécies de plantas que compartilham deste mecanismo de tolerância. Da mesma forma, existe uma especificidade do ácido orgânico que desempenha a resposta de tolerância ao $\mathrm{Al}$ entre as diferentes espécies. Além dos trabalhos em trigo, trabalhos em outras espécies podem ser encontrados, com os respectivos ácidos orgânicos exsudados: em milho, citrato (PELLET; GRUNES; KOCHIAN, 1995; KORN; JORGE; ARRUDA, 1997; PIÑEROS et al. 2002); em centeio, citrato e malato (LI; MA; MATSUMOTO, 2000); em triticale, citrato e malato (MA; TAKETA; YANG, 2000); em aveia, citrato e malato (ZHENG; MA; MATSUMOTO, 1998a); em cevada, citrato (ZHAO et al. 2003; MA et al., 2004); em soja, citrato (YANG et al. 2000; SILVA et al. 2001); em fumo, citrato (DELHAIZE; HEBB; RYAN, 2001); em Arabidopsis, malato (HOEKENGA et al., 2003); em sorgo, citrato (MAGALHAES, 2002); em nabo, citrato e malato 
(ZHENG; MA; MATSUMOTO, 1998a); em trigo sarraceno, oxalato (ZHENG; MA; MATSUMOTO, 1998b), entre outros em diferentes espécies.

O citrato é o mais comum entre as espécies como ácido orgânico exsudado na presença do Al, é também o mais efetivo entre os ácidos orgânicos por ser um ânion tricarboxilado, ele consegue formar quelatos com o $\mathrm{Al}^{3+}$ muito mais estáveis, se comparados com os quelatos formados pelo malato (ânion dicarboxilado). Desta forma, fica evidente a importância do citrato, como ácido orgânico envolvido na tolerância ao Al tóxico. Porém, o que não está elucidado ainda é como diferentes espécies regulam esta especificidade do ácido orgânico exsudado na presença do $\mathrm{Al}$, entre outras questões relacionadas ao metabolismo dos diferentes ácidos orgânicos e suas especificidades quanto à espécie.

Existe também diferença entre o local onde o ácido orgânico é exsudado, por exemplo, em trigo a exsudação do malato ocorre no ápice da raiz (até em torno de 0,2 a $0,3 \mathrm{~mm}$ da ponta da raiz), o que aumenta a eficiência da ação contra o Al, visto que é a zona crítica da raiz e requer a maior proteção do Al. Já no milho, o efluxo do citrato ocorre até $50 \mathrm{~mm}$ do ápice radicular mediante a presença do $\mathrm{Al}$ na solução do solo (PIÑEROS et al., 2002), e no sorgo, tanto o processo de exclusão do Al quanto o de ativação do citrato ocorre até os $30 \mathrm{~mm}$ do ápice radicular (MAGALHAES, 2002). Assim, parece que no milho e sorgo, parte do citrato exsudado de regiões da raiz muito além do ápice radicular não estejam diretamente envolvido com a tolerância ao Al.

Outra função importantíssima dos ácidos orgânicos esta relacionada com a fitodisponibilização do fósforo, uma vez que estes compostos são capazes de dissociar os complexos P-Al e P-Fe, formando compostos estáveis com o Al e Fe e liberando o P para a solução do solo (SPOSITO, 1989). Desta forma, a presença de grandes quantidades dessas substâncias no solo pode ter importantes implicações em química e nutrição de plantas (GARDNER; PARBERY; BARBER, 1982).

\section{Desintoxicação interna do Al}

Mais recentemente os pesquisadores têm dado atenção especial a espécies de plantas que apresentam a capacidade de acumular elevadas quantidades de $\mathrm{Al}$ em seus tecidos, como meio de desintoxicação interna do Al nas plantas. Estudos sobre duas espécies, hortênsia (Hydrangea macophylla) e trigo sarraceno (Fagopyrum esculentum), que acumulam Al, têm despertado interesse dos pesquisadores (MA et al., 1997; ZHENG; MA; MATSUMOTO, 1998b).

A hortênsia é uma planta ornamental que torna suas pétalas do vermelho ao azul quando o solo é acidificado. A alteração na cor é dada pela acumulação de complexos de $\mathrm{Al}$ nas pétalas. Esta espécie pode acumular até $3000 \mathrm{mg} \mathrm{L}^{-1}$ de $\mathrm{Al} \mathrm{em}$ suas folhas e pétalas, complexado com citrato (MA et al., 1997). Segundo o mesmo autor, no citosol a pH 7,0, este é um complexo extremamente forte, impossibilitando ao Al causar injúrias no citosol.

Em trigo sarraceno, (ZHENG; MA; MATSUMOTO, 1998b) mostraram que parte da tolerância ao Al envolvia exsudação de oxalato pelos ápices das raízes nesta espécie. Porém, também elevadas concentrações de Al nas folhas eram acumulados (até $15 \mathrm{mg} . \mathrm{L}^{-1}$ ) quando cultivado em solos ácidos (MA; RYAN; DELHAIZE, 2001). Anteriormente, (MA; MIYASAKA, 1998) também mostraram que a desintoxicação interna do Al pelos ácidos orgânicos não seria pela indução a partir da presença do elemento ao redor da raiz, pois não havia diferença entre a concentração de ácido oxálico nas células das folhas de Fagopirum com ou sem tratamento com Al. Em outro estudo sobre esta espécie, protoplastos e vacúolos de folhas que tinham acumulado $\mathrm{Al}$, foram isolados e encontrados mais de $80 \%$ do Al no protoplasto na forma de complexos de oxalato, e a maioria destes complexos seqüestrados no vacúolo (SHEN et al., 2002).

Outra espécie que vem merecendo atenção em termos de tolerância ao $\mathrm{Al}$, é o capim do gênero Brachiaria (Bracchiaria decumbens), espécie 
forrageira que é amplamente difundida nas regiões tropicais. A brachiária é extremamente tolerante ao Al, em um estudo hidropônico comparativo, revelou ser consideravelmente mais tolerante do que genótipos tolerantes de trigo, milho e triticale (WENZL et al., 2001). É admitido que existe apenas uma porção de exclusão de Al pelas raízes de brachiaria. Em outra espécie de brachiária, a brachiária-peluda (Bracchiaria ruziziensis), ocorreu a acumulação de duas vezes mais de $\mathrm{Al}$ em relação a $B$. decumbens nos ápices radiculares, porém não foi constatada a exsudação de ácidos orgânicos na superfície do ápice da raiz em ambas as espécies. Em estudo subseqüente, com intuito de investigar o processo de desintoxicação interna do Al (WENZL et al., 2002), identificou um incremento significativo de citrato nas pontas de raízes em ambas as espécies de brachiaria, e somente uma pequena fração deste ácido orgânico fora secretado pelo ápice radicular. $\mathrm{O}$ autor sugere que um processo interno de desintoxicação e seqüestro do Al através do citrato pode desempenhar importante papel na tolerância ao Al em ambas essas espécies. Possivelmente, estas espécies empenham importantes recursos em mecanismos e genes de tolerância ao Al, e está curiosidade levou nos últimos anos a muitos projetos de investigação genética e molecular das bases da tolerância ao Al, principalmente na $B$. decumbens.

\section{Exsudação de compostos fenólicos}

Os compostos fenólicos apresentam a peculiaridade de complexar metais, tais como o Al, além de ter ação como agente antioxidante em condições de estresse abióticos, por isso, estes compostos começaram a ser relacionados com a tolerância ao Al (MATSUMOTO et al., 1976; OFEIMANU et al., 2001). Estes pesquisadores reportam que compostos fenólicos formam fortes complexos com o $\mathrm{Al}$ a pH neutro (no citosol) e implicam em desintoxicação do $\mathrm{Al}$ internamente em ervas de chás, especialmente, e outras espécies que acumulam Al.
Porém, o processo da exsudação de compostos fenólicos ainda é pouco entendido, em termos de mecanismo de tolerância ao Al. A razão pelo qual não é dada tanta importância a este processo é devido ao fato de que em condições ácidas, o $\mathrm{Al}$ e $\mathrm{H}^{+}$ competem pelos sítios dos compostos fenólicos, o que reduz sua capacidade de complexação comparado aos dos ácidos orgânicos.

Mesmo assim, Kidd et al. (2001) reportam correlações entre exsudação de flavonóides através da presença do Al, e as diferenças de tolerância ao Al entre três genótipos de milho. Este autor sugere que os compostos fenólicos provavelmente tenham um importante papel na desintoxicação do Al na rizosfera que circunda o ápice radicular.

\section{Incremento do $\mathrm{pH}$ da rizosfera via influxo de $\mathrm{H}^{+}$}

Este foi um mecanismo bastante defendido no começo dos estudos de tolerância ao Al. Tal processo se basea no fato de que se a raiz pode incorporar o íon $\mathrm{H}^{+}$e aumentar o $\mathrm{pH}$ ao redor do ápice radicular, isto reduziria a atividade do Al tóxico na rizosfera. Vários trabalhos publicados mostraram que não foi efetivamente comprovado este processo (MARTELL; MOTEKAITIS, 1989; TAYLOR, 1991; DODGE; HIATT, 1992). O trabalho de Degenhardt et al. (1998) é considerado básico sobre este mecanismo. Estes autores, avaliando mutantes de Arabidopsis selvagem que não apresentavam exsudação de nenhuma espécie de ácido orgânico, associaram a tolerância ao $\mathrm{Al}$ destes mutantes ao maior influxo de íons $\mathrm{H}^{+}$pelo ápice radicular. Porém, seus resultados são questionados por outros pesquisadores que consideram a quantidade de influxo de $\mathrm{H}^{+}$que resultou no incremento do $\mathrm{pH}$ (modificou de 4,4 para 4,5) na superfície do ápice radicular muito aquém do suficiente para o decréscimo da atividade do $\mathrm{Al}^{3+}$ ao redor da ponta da raiz e permitir o desenvolvimento da raiz. A partir disso, este mecanismo diretamente relacionado com a tolerância ao Al está bastante desacreditado atualmente. 


\section{Outros mecanismos potenciais de tolerância ao Al}

Alguns possíveis mecanismos de tolerância ao $\mathrm{Al}$, porém somente em fase de especulações por parte dos pesquisadores, poderão vir a ser desvendados futuramente. Entre os mecanismos de exclusão do Al são considerados possíveis outros exsudatos orgânicos quelantes do $\mathrm{Al}$ ainda não descobertos, formação de barreiras via componentes que alteram o $\mathrm{pH}$ da rizosfera, complexação do Al por mucilagens secretadas pelas raízes e exclusão do $\mathrm{Al}$ acumulado por algum transportador específico do Al. Entre os mecanismos de desintoxicação interna do Al, é especulada a fixação do Al na parede celular e a complexação no simplasto via diferentes compostos orgânicos.

\section{Situação Atual e Perspectivas}

No Brasil, há uma grande carência de trabalhos desenvolvidos e publicados caracterizando genótipos de espécies importantes quanto aos mecanismos associados à tolerância ao Al. Neste sentido, Menosso et al. (2001) mostraram que cultivares de soja tolerantes ao $\mathrm{Al}$ podem ser diferenciadas das sensíveis pelo maior acúmulo de ácido cítrico. Outros trabalhos nacionais mostram a exsudação de ácidos orgânicos por algumas espécies, porém não fazem relação com estímulos causados pela presença do Al. Em raízes de cafeeiro, Melo Silva et al. (2002) detectaram ácido cítrico, oxálico, acético, butírico e propiônico. Franchini et al. (2001) estudando compostos orgânicos responsáveis pela mobilização de cátions no solo, detectaram uma série de ácidos orgânicos exsudados por nabo, tremoço, aveia preta, soja e trigo.

Por outro lado, a literatura internacional é vasta em publicações correlacionando ácidos orgânicos com a tolerância ao Al. Assim, a intensa atividade na pesquisa nos últimos anos tem promovido um rápido progresso no entendimento dos mecanismos de tolerância ao Al. O melhor entendimento, combinado com os esforços do melhoramento genético de plantas já tem resultados positivos em produtividade de grãos em solos ácidos em regiões tropicais (BARCELÓ; POSCHENRIEDER, 2002). Todavia, existe ainda uma deficiência de informações sobre as bases do transporte do Al na planta e as inter-relações entre quelatização do Al pelos exsudatos das raízes, exclusão, absorção, transporte do $\mathrm{Al}$ e acumulação do $\mathrm{Al}$ nos vacúolos das raízes e folhas. Entretanto, a melhor compreensão destes processos e suas relações com a utilização eficiente do fósforo e a produtividade das culturas torna-se fundamental para o melhoramento genético no desenvolvimento de novos genótipos.

Vem aumentando a consciência nos trabalhos de pesquisa, de que a solução dos problemas dos solos ácidos não somente está relacionada com a tolerância ao Al, mas também envolve incremento na eficiência da absorção de fósforo (P) e outros nutrientes limitantes, bem como tolerância a outros metais tóxicos, em condições ácidas. As pesquisas têm identificado constantemente genes que revelam relação com a tolerância ao $\mathrm{Al}$ e estas descobertas devem abrir novas fronteiras para as bases genéticas e moleculares da tolerância a esse elemento, assim como promover novos recursos moleculares para o melhoramento das principais culturas quanto a tolerância ao Al via seleção assistida por marcadores e pela biotecnologia.

\section{Referências}

BARCELÓ, J.; POSCHENRIEDER, C. Fast root growth responses, root exudates, and internal detoxification as clues to the mechanisms of aluminium toxicity and resistance: a review. Environmental and Experimental Botany, Oxford, v.48, n.1, p.75-92, 2002.

BECKMANN, I. Sobre o cultivo e melhoramento do trigo (Triticum vulgare Vill) no sul do Brasil. Agronomia Sulriograndense, Porto Alegre, v.1, n.1, p.64-72. 1954.

CASSIOLATO, M. E.; MEDA, A. R.; PAVAN, M. A.; MIYAZAWA, M.; OLIVEIRA, J. C. Evaluation of oat extracts on the efficiency of lime in soil. Brazilian Archives of Biology and Technology, Curitiba, v.43, n.5, p.533-536, 2000. 
DEGENHARDT, J.; LARSEN, P. B.; HOWELL, S. H.; KOCHIAN, L. V. Aluminum resistance in the Arabidopsis mutant alr-104 is caused by an aluminum-induced increase in rhizosphere pH. Plant Physiology, Rockville, v.117, n.1, p.19-27, 1998.

DELHAIZE, E.; CRAIG, S.; BEATON, C. D.; BENNET, R. J.; JAGADISH, V. C.; RANDALL, P. J. Aluminum tolerance in wheat (Triticum aestivum L.): I. Uptake and distribution of aluminum in root apices. Plant Physiology, Rockville, v.103, n.3, p.685-693, 1993.

DELHAIZE, E.; HEBB, D. M.; RYAN, P. R. Expression of a Pseudomonas aeruginosa citrate synthase gene in tabacco is not associated with either enhanced citrate accumulation or efflux. Plant Physiology, Rockville, v.125, n.4, p.2059-2067, 2001.

DELHAIZE, E.; RYAN, P. R.; RANDALL, P. J. Aluminum tolerance in wheat (Triticum aestivum L.): II. Aluminumstimulated excretion of malic acid from root apices. Plant Physiology, Rockville, v.103, n.3, p.695-702, 1993.

DODGE, C. S.; HIATT, A. J. Relationship of $\mathrm{pH}$ to ion uptake imbalance by varieties of wheat (Triticum vulgare). Agronomy Journal, Madison v.64, n.4, p.476-481, 1992.

FAGERIA, N. K. Tolerância diferencial de cultivares de arroz ao alumínio em solução nutritiva. Pesquisa Agropecuária Brasileira, Brasília, v.17, n.1, p.1-9, 1982.

FAGERIA, N. K.; BALIGAR, V. C.; WRIGHT, R. J. The effects of aluminum on growth and uptake of $\mathrm{Al}$ and $\mathrm{P}$ by rice. Pesquisa Agropecuária Brasileira, Brasília, v.24, n.6, p.677-682, 1989.

FAGERIA, N. K.; ZIMMERMANN, F. J. P. Seleção de cultivares de arroz para tolerância a toxidez de alumínio em solução nutritiva. Pesquisa Agropecuária Brasileira, Brasília, v.14, n.2, p.141-147, 1979.

FRANCHINI, J. C.; GONZALES-VILA, F. J.; CABRERA, F.; MIYAZAWA, M.; PAVAN, M. A. Rapid transformations of plant water-soluble organic compounds in relation to cation mobilization in an acid Oxisol. Plant and Soil, Netherlands, v.231, n.1, p.55-63, 2001.

FREITAS, F. A.; KOPP, M. M.; SOUSA, R. O.; ZIMMER, P. D.; CARVALHO, F. I. F.; OLIVEIRA, A. C. Absorção de $\mathrm{P}, \mathrm{Mg}, \mathrm{Ca}$ e $\mathrm{K}$ e tolerância de genótipos de arroz submetidos a estresse por alumínio em sistemas hidropônicos. Ciência Rural, Santa Maria, v.36, n.1, p.7279, 2006.

GARDNER, W. K.; PARBERY, D. G.; BARBER, D. A. The acquisition of phosphorus by Lupinus albus L. I. Some characteristics of the soil/root interface. Plant and Soil, Dordrecht, v.68, n.1, p.19-32, 1982.
GRIME, J. P.; HODGSON, J. G. An investigation of the ecological significance of lime chlorosis by means of large scale comparative experiments. In: RORISON, I. H. Ecological aspects of the mineral nutrition of plants. Sheffield: British Ecological Society, 1969. p.67-69.

HOEKENGA, O. A.; VISION, T. J.; SHAFF, J. E.; MONFORTE, A. J.; LEE, G. P.; HOWELL, S. H.; KOCHIAN, L. V. Identification and characterization of aluminum tolerance loci in Arabidopsis (Landsberg erecta $\mathrm{x}$ Columbia) by quantitative trait locus mapping. A physiologically simple but genetically complex trait. Plant Physiology, Rockville, v.132, n.2, p.936-948, 2003.

HOWELER, R.H.; CADAVID, L.F. Screening of rice cultivars for tolerance to $\mathrm{Al}$ toxicity in nutrient solutions and compared with a field screening method. Agronomy Journal, Madison, v.68, n.5, p.551-555, 1976.

JONES, D. L.; KOCHIAN, L. V. Aluminum inhibition of the inositol 1,4,5-triphosphate signal transduction pathway in wheat roots: a role of aluminum toxicity. Plant Cell, Rockville, v.7, n.11, p.1913-1922, 1995.

KELTJENS, W. G.; VAN LOENEN, E. Effects of aluminum on growth and chemical composition of hidroponically grown seedlings of five different forest tree species. Plant and Soil, Dordrecht, v.119, n.1, p.39-50, 1989.

KIDD, P. S.; LLUGANY, M.; POSCHENRIEDER, C.; GUNSE, B.; BARCELO, J. The role of root exudates in aluminum resistance and silicon-induced amelioration of aluminum toxicity in three varieties of maize (Zea mays L.). Journal of Experimental Botany, Oxford, v.52, n.359, p.1339-1352, 2001.

KOCHIAN, L. V. Cellular mechanisms of aluminum toxicity and resistance in plants. Annual Review of Plant Physiology and Plant Molecular Biology, Palo Alto, v.46, n.1, p.237-260, 1995.

KOCHIAN, L. V.; JONES, D. L. Aluminum toxicity and resistance in plants. In: YOKEL, R.; GOLUB, M. S. Research Issues in Aluminum Toxicity. Bristol: Taylor and Francis Publishers, 1997. p.69-90.

KORN, M.; JORGE, R. A.; ARRUDA, P. Aluminuminduced organic acid exudation by roots of an aluminumtolerant tropical maize. Phytochemistry, Oxford, v.45, n.4, p.675-681, 1997.

LI, X. F.; MA, J. F.; MATSUMOTO, H. Pattern of aluminum-induced secretion of organic acids differs between rye and wheat. Plant Physiology, Rockville, v.123, n.4, p.1537-1544, 2000.

MA, J. F.; FURUKAWA, J. Recent progress in the research of external Al detoxification in higher plants: a minireview. Journal of Inorganic Biochemistry, New York, v.97, n.1, p.46-51, 2003. 
MA, J. F.; HIRADATE, S.; NOMOTO, K.; IWASHITA, T.; MATSUMOTO, $\mathrm{H}$. Internal detoxification mechanism of $\mathrm{Al}$ in hydrangea (Identification of $\mathrm{Al}$ form in the leaves). Plant Physiology, Rockville, v.113, n.4, p.1033-1039, 1997.

MA, J. F.; NAGAO, K.; SATO, K.; ITO, H.; FURUKAWA, J.; TAKEDA, K. Molecular mapping of a gene responsible for Al-activated secretion of citrate in barley. Journal of Experimental Botany, Oxford, v.55, n.401, p.1335-1341, 2004.

MA, J. F.; RYAN, P. R.; DELHAIZE, A. Aluminium tolerance in plants and the complexing role of organic acids. Trends Plant Science, London, v.6, n.6, p.273-278, 2001.

MA, J. F.; TAKETA, S.; YANG, Z. M. Aluminum tolerance genes on the short arm of chromosome $3 \mathrm{R}$ are linked to organic acid release in triticale. Plant Physiology, Rockville, v.122, n.3, p.687-694, 2000.

MA, Z.; MIYASAKA, S. C. Oxalate exudation by Taro in response to Al. Plant Physiology, Rockville, v.118, n.3, p.861-865, 1998.

MAGALHAES, J. V. Molecular genetic and physiological investigation of aluminum tolerance in sorghum (Sorghum bicolor L. Moench). 2002. PhD (Thesis) Cornell University, New York.

MARTELL, A. E.; MOTEKAITIS, R. J. Coordination chemistry and specification of $\mathrm{Al}$ in aqueous solution. In: LEWIS, T. E. Environmental chemistry and toxicology of aluminum. Chelsea, MI: Lewis, 1989. p.3-17.

MATSUMOTO, H. Cell biology of aluminum toxicity and tolerance in higher plants. International Review Cytology, San Diego, v.200, p.1-46, 2000.

MATSUMOTO, H.; HIRASAWA, E.; MORIMURA, S.; TAKAHASHI, E. Localization of aluminum in tea leaves. Plant Cell Physiology, Kioto, v.17, n.3, p.627-631, 1976.

MELO SILVA, F. A.; NOGUEIRA, F. D.; GUIMARÃES, P. T. G.; GODINHO, A.; MALTA, M. R.; Determinação de ácidos orgânicos de baixo peso molecular na rizosfera de cafeeiro por cromatografia líquida de alta eficiência (CLAE). Ciência e Agrotecnologia, Lavras, v.esp., p.1391-1395, 2002.

MENOSSO, O. G.; COSTA, J. A.; ANGHINONI, I.; BOHNEN, H. Crescimento radicular e produção de ácidos orgânicos em cultivares de soja com diferentes tolerâncias ao alumínio. Pesquisa Agropecuária Brasileira, Brasília, v.36, n.11, p.1339-1345, 2001.

OFEI-MANU, P.; WAGATSUMA, T.; ISHIKAWA, S.; TAWARAYA, K. The plasma membrane strength of the root-tip cells and root phenolic compounds are correlated with Al tolerance in several common woody plants. Soil Science Plant Nutrition, Tokyo, v.47, n.2, p.359-375, 2001.
OLMOS, I. R.; CAMARGO, M. N. Ocorrência de alumínio tóxico nos solos do Brasil, sua caracterização e distribuição. Ciência e Cultura, Rio de Janeiro, v.28, n.2, p.171-180, 1976.

PELLET, D. M.; GRUNES, E. L.; KOCHIAN, L.V. Organic acid exudation as an aluminum-tolerance mechanism in maize (Zea mays L.). Planta, New York, v.196, n.4, p.788795, 1995.

PIÑEROS, M. A.; MAGALHAES, J. V.; ALVES, V. M. C.; KOCHIAN, L. V. The physiology and biophysics of an aluminum tolerance mechanism based on root citrate exudation in maize. Plant Physiology, Rockville, v.129, n.3, p.1194-1206, 2002.

RINCÓN, M.; GONZALES, R. G. Aluminum partitioning intact roots of aluminum-tolerant and aluminum-sensitive wheat (Triticum aestivum L.) cultivars. Plant Physiology, Rockville, v.99, n.3, p.1021-1028, 1992.

RYAN, P. R.; DELHAIZE, E.; RANDALL, P.J. Characterization of Al-stimulated efflux of malate from the apices of Al-tolerant wheat roots. Planta, New York, v.196, n.1, p.103-110, 1995a.

RYAN, P. R.; DELHAIZE, E.; RANDALL, P. J. Malate efflux from root apices and tolerance to aluminum are highly correlated in wheat. Australian Journal of Plant Physiology, Collingwood, v.22, n.4, p.531-536, 1995 b.

RYAN, P.R.; DITOMASO, J.M.; KOCHIAN, L.V. Aluminum toxicity in roots - An investigation of spatial sensitivity and the role of the root cap. Journal of Experimental Botany, Oxford, v.44, n.2, p.437-446, 1993.

SALVADOR, J. O.; MOREIRA, A.; MALAVOLTA, E.; CABRAL, C. P. Influência do alumínio no crescimento e na acumulação de nutrientes em mudas de goiabeira. Revista Brasileira de Ciência do Solo, Campinas, v.24, n.4, p.787-796, 2000.

SCHIER, G.A. Response of red spruce and balsam fir seedlings to aluminium toxicity in nutrient solutions. Canadian Journal of Forest Research. Ottawa, v.15, n.1, p.29-33, 1985.

SHEN R.F.; MA, J.F.; KYO, M.; IWASHITA, T. Compartmentation of aluminium in leaves of an Alaccumulator, Fagopirum esculentum Moench. Planta, New York, v.215, n.3, p.394-398, 2002.

SILVA, I. R.; SMYTH T. J.; MOXLEY, D. F.; CARTER, T. E.; ALLEN, N. S.; RUFTY, T. W. Aluminum accumulation at nuclei of cells in the root tip. Fluorescence detection using lumogallion and confocal laser scanning microscopy. Plant Physiology, Rockville, v.123, n.2, p.543-552, 2000. 
SILVA, I. R; SMYTH, T. J.; RAPER, C. D.; CARTER, T. E.; RUFTY, T. W. Differential aluminum tolerance in soybean: An evaluation of the role of organic acids. Physiologia Plantarum, Oxford, v.112, n.2, p.200-210, 2001.

SILVA, J. B. C.; NOVAIS, R. F.; SEDIYAMA, C. S. Comportamento de genótipos de soja em solo com alta saturação de alumínio. Pesquisa Agropecuária Brasileira, Brasília, v.19, n.3, p.287-298, 1984.

SIVAGURU, M.; BALUSKA, F.; VULKMANN, D.; FELLE, H. H.; HORST, W. J. Impacts of aluminum on the cytoskeleton of maize root apex: short-term effects on the distal part of the transition zone. Plant Physiology, Rockville, v.119, n.3, p.1073-1082, 1999.

SPOSITO, G. The chemistry of soils. New York: Oxford University, 1989.

TAYLOR, G. J. Current views of the aluminum stress response: the physiological basis of tolerance. In: RANDALL, D. D.; BLEVINS, D. G.; MILES, C. D. (eds.). Current Topics in Plant Biochemistry Physiology, Columbia, v.10, p.57-93, 1991.

TAYLOR, G. J.; MCDONALD-STEPHENS, J. L.; HUNTER, D. B.; BERTSCH, P. M.; ELMORE, D.; RENGEL, Z.; REID, R. J. Direct measurement of aluminum uptake and distribution in single cells of Chara corallina. Plant Physiology, Rockville, v.123, n.3, p.987-996, 2000.

THAWORNWONG, N.; DIEST, A. V. Influence of high acidity and aluminum on the growth of lowland rice. Plant and Soil, Netherlands, v.41, n.1, p.141-159, 1974.

VON UEXKÜLL, H. R.; MUTERT, E. Global extend, development and economic - impact of acid soils. Plant and Soil, Dordrecht, v.171, n.1, p.5-19, 1995.
WENZL, P.; CHAVES, A. L.; PATIÑO, G. M.; MAYER, J. E.; RAO, I. M. Aluminum stress stimulates the accumulation of organic acids in root apices of Brachiaria species. Journal of Plant Nutrition and Soil Science, Weinheim, v.165, n.5, p.582-588, 2002.

WENZL, P.; PATIÑO, G. M.; CHAVES, A. L.; MAYER, J. E.; RAO, I. M. The high level of aluminum resistance in signalgrass is not associated with known mechanisms of external aluminum detoxification in root apices. Plant Physiology, Rockville, v.125, n.3, p.1473-1484, 2001.

YANG, Z. M.; SIVAGURU, M.; HORST, W. J.; MATSUMOTO, H. Aluminum tolerance is achieved by exudation of citric acid from roots of soybean (Glycine max). Physiologia Plantarum, Oxford, v.110, n.1, p.72-77, 2000.

ZHANG, W.H.; RENGEL Z. Aluminium induces an increase in cytoplasmic calcium in intact wheat root apical cells. Australian Journal of Plant Physiology, Collingwood, v.26, n.5, p.401-409, 1999.

ZHAO, Z.; MA, J. F.; SATO, K.; TAKEDA, K. Differential Al resistance and citrate secretion in barley (Hordeum vulgare L.). Planta, New York, v.217, n.5, p.794-800, 2003.

ZHENG, S. J.; MA, J. F.; MATSUMOTO, H. Continuous secretion of organic acids in related to aluminum resistance during relatively long-term exposure to aluminum stress. Physiologia Plantarum, Oxford, v.103, n.2, p.209-214, 1998a.

ZHENG, S. J.; MA, J. F.; MATSUMOTO, H. High aluminum resistance in buckwheat: I. Al-induced specific secretion of oxalic acid from root tips. Plant Physiology, Rockville, v.117, n.3, p.745-751, 1998 b. 